\title{
Risk-based cost-benefit analysis of climate adaptation measures for Australian contemporary houses under extreme winds
}

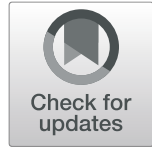

\author{
Hao Qin ${ }^{*}$ and Mark G. Stewart
}

\begin{abstract}
Climate adaptation measures improve housing resilience to extreme winds, and reduce economic losses associated with wind and rainfall damage under a changing climate. Several adaptation measures are adopted in this study for Australian contemporary houses subjected to non-cyclonic windstorms to either reinforce the building envelope or increase the water resistance of building interior. A risk-based cost-benefit analysis is conducted to evaluate the cost-effectiveness of these adaptation measures that considers the effect of construction defects. It was found that the annual expected losses for houses in Brisbane with construction defects are considerably higher than those without considering construction defects, whereas the influence of construction defects is lower for the Melbourne houses. The cost-benefit analysis reveals that strengthening windows is cost-effective for Brisbane and Melbourne houses. Installing window shutters significantly reduces economic risks associated with extreme winds and is costeffective for houses in Brisbane. Adaptation measures are generally not cost-effective for Melbourne houses due to lower extreme wind speed and associated rainfall.
\end{abstract}

Keywords: Australian contemporary houses, Non-cyclonic windstorms, Economic losses, Construction defects, Riskbased cost-benefit analysis, Climate adaptation

\section{Introduction}

Severe windstorm is one of the major natural disasters in Southeast Australia, which causes millions of annual losses for housing [7]. The climate change impact on the intensity of windstorm and associated rainfall impose more uncertainty in housing damage risks. Climate adaptation measures are thus of significant importance for the improvement of building resilience to windstorms, and the reduction of economic losses associated with wind and rainfall damage under a changing climate. However, the adoption of a specific climate adaptation measure is still in question if its cost-effectiveness is unclear, and therefore there is a need to quantify the costs and benefits of adaptation measures to assess their economic viability.

\footnotetext{
*Correspondence: hao.qin@uon.edu.au

Centre for Infrastructure Performance and Reliability, The University of Newcastle, Newcastle, New South Wales 2308, Australia
}

Many cost-benefit studies have been reported in the literature for houses subjected to tropical cyclones or hurricanes in the United States (e.g. [19, 21, 41, 42]) and Australia (e.g. [35, 39]). New South Wales, Victoria and southeastern Queensland of Southeast Australia have nearly $70 \%$ of Australia's population, and are classified as non-cyclonic regions in AS/NZS 1170.2 [4]. Only about $5 \%$ of Australia's population live in cyclonic regions. Residential construction in Southeast Australia comprises of a large portion of metal-clad contemporary houses, which generally have less wind resistance than houses in cyclonic regions of Australia, and differ from North American houses in materials, construction techniques and building design. Quantitative studies regarding wind risk mitigation and climate adaptation for Australian contemporary houses subjected to noncyclonic windstorms are scarce in the literature. The development of feasible climate adaptation measures and
Springer Open (c) The Author(s). 2020 Open Access This article is licensed under a Creative Commons Attribution 4.0 International License, which permits use, sharing, adaptation, distribution and reproduction in any medium or format, as long as you give appropriate credit to the original author(s) and the source, provide a link to the Creative Commons licence, and indicate if changes were made. The images or other third party material in this article are included in the article's Creative Commons licence, unless indicated otherwise in a credit line to the material. If material is not included in the article's Creative Commons licence and your intended use is not permitted by statutory regulation or exceeds the permitted use, you will need to obtain permission directly from the copyright holder. To view a copy of this licence, visit http://creativecommons.org/licenses/by/4.0/. 
the quantification of their cost-effectiveness are still needed to improve the resilience of residential communities in Australia against wind hazards.

Wind risk mitigation and climate adaptation include measures to either enhance the design during initial construction or retrofit (i.e. upgrade or strengthen) an existing house. Recently, Qin \& Stewart [26] developed a probabilistic risk assessment framework for Australian contemporary houses subjected to wind and rainfall damage, and found that most losses result from damage to building interior and contents caused by rainwater intrusion through breaches (e.g. openings due to metal roof sheeting loss and window breakage) and gaps in the building envelope. A set of climate adaptation measures are thus proposed in this study to reinforce the building envelope against wind and improve the water resistance of building interior: (i) strengthening connections for metal roof cladding, (ii) installing shutters for windows, (iii) improving window resistance, and (iv) using waterresistant materials for the building interior.

Most studies regarding the cost-benefit analysis of wind mitigation and climate adaptation measures for housing in Australia are based on empirical vulnerability models to quantify the wind and rainfall damage (e.g. [20, 33, 36, 39]). For example, Stewart [36] employed expert-elicited wind vulnerability curves to assess the housing losses with enhanced building design. Smith \& Henderson [33] used insurance data to estimate the cost and benefit of various retrofit and mitigation solutions for houses in cyclonic regions of Australia. However, these empirical vulnerability models have very limited ability to assess the performance of detailed mitigation or adaptation measures applied to specific housing components for wind risk reduction [43]. To overcome this limitation, the cost-benefit analysis in this study is conducted based on the probabilistic risk assessment method developed by Qin \& Stewart [26], which systematically integrates engineering judgement, datadriven and engineering-based models for the quantification of extreme wind and associated rainfall, wind damage to housing, rainwater intrusion and economic losses. Such cost-benefit analysis provides a risk-based performance assessment and decision support for the proposed climate adaptation measures.

It has been widely acknowledged that construction defects may significantly increase housing vulnerability under wind hazards [34, 45]. Construction defects are common for residential construction, which may also affect the cost-effectiveness of relevant climate adaptation measures. For example, an adaptation measure may provide little reduction in economic losses for houses with good construction quality but it might be worthwhile for houses that have defective components. To the best knowledge of the authors, the influence of construction defects on the assessment of wind damage risks and cost-effectiveness of mitigation or adaptation measures has not yet been taken into account in risk and costbenefit studies. A recent probabilistic model for construction defects in housing by Qin \& Stewart [27] is thus incorporated into the present study to examine the effect of construction defects.

The cost-effectiveness of a climate adaptation measure is evaluated in terms of net present value (NPV) that is equal to the benefit minus the cost. An adaptation measure is considered to be economically viable if NPV $>0$, which is analogous to the benefit-to-cost ratio or lifecycle cost analysis used in many other studies (e.g. [6, $20,21,41])$. A break-even economic assessment (e.g. [36]) is also adopted in this study to assess the conditions under which an adaptation measure is costeffective. The break-even analysis is conducted when considerable uncertainties are involved in the assessment of risk reduction and adaptation cost due to either the model limitations and/or a lack of data. As the climate projections for many regions of Australia are under great uncertainty, a scenario-based approach is used in this study to examine the climate change impacts on the cost-benefit analysis.

\section{Risk-based decision-making \\ Wind risk}

The risk from extreme wind events is expressed as [36]

$$
E(L)=\sum \operatorname{Pr}(C) \operatorname{Pr}(H \mid C) \operatorname{Pr}(D S \mid H) \operatorname{Pr}(L \mid D S) L
$$

where $\operatorname{Pr}(C)$ is the annual probability that a specific climate scenario will occur, $\operatorname{Pr}(H \mid C)$ is the annual probability of a wind hazard conditional on the climate, $\operatorname{Pr}(D S \mid H)$ is the probability of a damage state conditional on the hazard (also known as fragility), $\operatorname{Pr}(L \mid D S)$ is the conditional probability of a loss given occurrence of the damage, and $L$ is the loss or consequence if full damage occurs. The summation sign in Eq. (1) refers to the summation of a number of possible climate scenarios, hazards, damage states and losses. If the probability that a specific climate scenario will occur, $\operatorname{Pr}(C)$ is too unreliable, then a scenario-based analysis where climate scenario probability is decoupled from Eq. (1) is typically adopted for risk assessment and decision analysis (e.g. [36, 38]).

\section{Cost-benefit analysis}

In this study, the cost-effectiveness of a climate adaptation measure is evaluated based on the NPV, which is calculated as

$$
\mathrm{NPV}=E(L) \Delta R+\Delta B-C_{\text {adapt }}
$$

where $\Delta R$ is the reduction in risk due to the adaptation measure, $E(L)$ is the risk for the house without any 
adaptation measures (i.e. 'business as usual') given by Eq. (1), $\Delta B$ is the co-benefit of adaptation such as reduced losses to other hazards, increased energy efficiency, etc., and $C_{\text {adapt }}$ is the cost for climate adaptation. For an adaptation measure, $\Delta R$ can vary from 0 to $100 \%$. If the adaptation measure is applied at the initial design/construction stage, $C_{\text {adapt }}$ is the extra money spent on a stronger design/construction. For retrofitting, $C_{\text {adapt }}$ is the cost to remove the old housing component, if applicable, plus the cost to upgrade the component. All the climate adaptation measures (see Section "Climate adaptation") considered in this study only require a one-off expense. The present study focuses on the wind risk mitigation, and therefore the quantification of $\Delta B$ is not included. The NPV calculated in this study is a dependent variable mainly due to the variability of $\Delta R$. The confidence bounds of NPV or the probability of NPV $>0$ can also be calculated. However, as the decision analysis in this study is based on a maximum expected net benefit/return criterion, only the mean NPV is of interest. Note that the above equations can be generalised for any time period, discounting of future costs and detailed time-dependent cost and damage consequences.

In addition to the NPV, a break-even analysis is also employed in this study as a decision tool when significant uncertainties are involved in the estimation of $\Delta R$ and $C_{\text {adapt }}$ due to the limitation of relevant models and/or a lack of information. The break-even analysis can be viewed as a type of retrospective analysis, the output of which is the condition that enables the mean of NPV to be zero. A climate adaptation measure is not cost-effective if the risk reduction provided by the measure is lower than, or the adaptation cost is higher than the predicted break-even value. Decision-makers can then judge whether an adaptation measure meets these break-even values.

\section{Representative contemporary house}

The risk-based cost-benefit analysis is conducted for the representative contemporary housing built in the southeastern Australian suburbs of Melbourne and Brisbane. These two cities account for about 30\% of Australia's population. The representative contemporary house is a timber-framed brick-veneer construction with $21.5^{\circ}$ timber roof trusses at $600 \mathrm{~mm}$ spacings on a complex hipend roof. Windows are generally horizontal sliding aluminum or timber awning with a brick on edge or terracotta tiled window sill. Roof cladding is $762 \mathrm{~mm}$ wide corrugated metal sheeting. Metal top-hat battens are attached to timber roof trusses at $900 \mathrm{~mm}$ spacings. The dimension, shape and construction type of the representative contemporary house in Brisbane and Melbourne were determined by field surveys completed by the Cyclone Testing Station (CTS), James Cook University (JCU) (see [22] for more details). Figure 1 shows the
$3 \mathrm{D}$ and plan view of the representative one-storey house [22]. The design of structural members and components for housing subjected to wind loading is based on the design wind classifications specified in AS 4055 [3] for different site conditions. According to AS 4055 [3], most suburban houses in Brisbane have a design wind classification of $\mathrm{N} 2$ or $\mathrm{N} 3$ excluding those built on the topthird zone of a hill, ridge or escarpment. A design wind classification of N1 or N2 is appropriate for most suburban houses in Melbourne. Thus, the representative contemporary house herein is considered to have design wind classifications ranging from N1 to N3.

\section{Probabilistic risk assessment}

A probabilistic risk assessment (PRA) method developed by Qin \& Stewart [26] provides the basis for risk-based decision-making to mitigate housing damage risks from non-cyclonic windstorms under a changing climate. The PRA framework includes probabilistic models for wind hazard and associated rainfall, reliability-based wind damage assessment, rainwater intrusion evaluation and loss estimation. The economic losses considered for contemporary houses arise from wind damage to metal roof cladding and timber roof framing, windward windows, and rainwater damage to building interior and contents as well as the loss of use. This is based on post-damage surveys (e.g. [18, 23]) that the majority of losses to contemporary houses result from wind damage to roof and fenestrations (especially windows), and the subsequent rainwater intrusion. The damage to other housing components (e.g. walls) is rare for contemporary houses in non-cyclonic regions of Australia.

\section{Hazard modelling and climate change impacts Extreme wind speed}

Extreme value analysis is conventionally used to predict extreme wind speed based on recorded data [15]. The Gumbel distribution is employed to model the annual maximum gust wind speed (the maximum $0.2 \mathrm{~s}$ gust velocity at $10 \mathrm{~m}$ height in open terrain) in non-cyclonic regions of Australia [44]. Figure 2 shows the relationship between gust wind speed $v$ and return period obtained from the analyses by Wang et al. [44].

\section{Rainfall associated with extreme winds}

When assessing the rainwater damage to building interior and contents, the joint probability of wind speed, rainfall intensity and storm duration is needed. The exponential distribution is connected to the Poisson arrival process, and commonly used to model storm duration (e.g. $[9,17])$. The gamma distribution is a widely used parent distribution for rainfall intensity during a storm (e.g. [16, 32]).

According to Qin \& Stewart [26], the storm duration $\left(D_{u r}\right)$ is modelled by a two-parameter exponential distribution. The average rainfall intensity $R_{h}$ that is non-zero (i.e. 


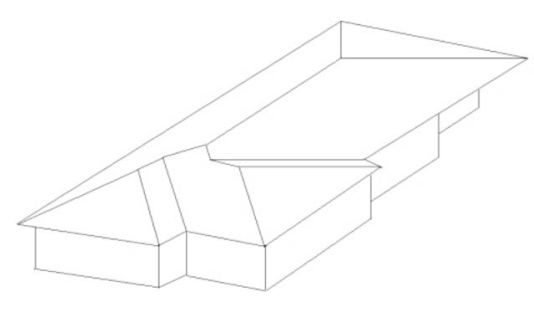

(a) 3D view

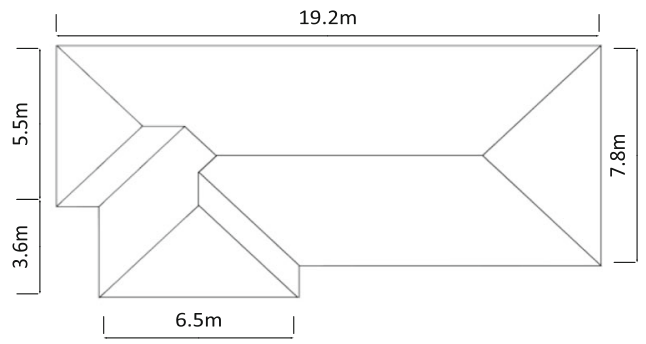

(b) Plan view

Fig. 1 One-storey representative contemporary house

rainfall concurs with strong wind) during an extreme windstorm is modelled by a gamma distribution as a function of the storm duration $D_{u r}$. The probability of no rain during a windstorm is also taken into account. A twenty-year length (1996 to 2015) of half hourly wind and rainfall data for severe windstorms from two weather stations, i.e. Archerfield airport in Brisbane and Moorabbin airport in Melbourne, were used to estimate the parameters in the hazard model. Figure 3 shows the exponential probability plots for $D_{u r}$ given by Qin \& Stewart [26]. It is estimated that the probability of no rain during a windstorm is $25.6 \%$ and $45.9 \%$ for Brisbane and Melbourne, respectively. Figure 4 shows the mean and quantile values of $R_{h}$ produced by the gamma model as a function of $D_{u r}$ as well as the average rainfall intensity data [26]. Figures 3 and 4 reveal that Brisbane tends to have shorter windstorms with more intense rainfall (e.g. thunderstorms), whereas windstorms in Melbourne are generally longer with lower average rainfall intensity. See Qin \& Stewart [26] for more details about the hazard modelling and statistical analysis. Note that the probabilistic and statistical models for extreme wind and associated rainfall described in this paper are data-driven rather than relying on physical processes of the natural phenomena.

\section{Climate change projections}

Climate change influences the extreme wind speed and associated rainfall intensity. The latest projections $[8,10]$ for changes in extreme wind speed in Brisbane and Melbourne are summarised in Table 1 for medium and high $\mathrm{CO}_{2}$ emission scenarios RCP 4.5 and RCP 8.5, respectively, to 2090. Extreme wind projections for Melbourne are only available for RCP 8.5 (changes are not available for RCP 4.5). A drying trend with declining annual average rainfall is predicted for Brisbane and Melbourne, while extreme rainfall is projected to become more intense due to increasing water-holding capacity of the atmosphere under a warmer climate $[8,10]$. However, the quantitative projections for rainfall concurred with strong winds in a future climate are not available because the climate change impacts considering compound events (e.g. simultaneous occurrence of extreme wind and rainfall) in Australia remains unclear [46]. A high level of uncertainty

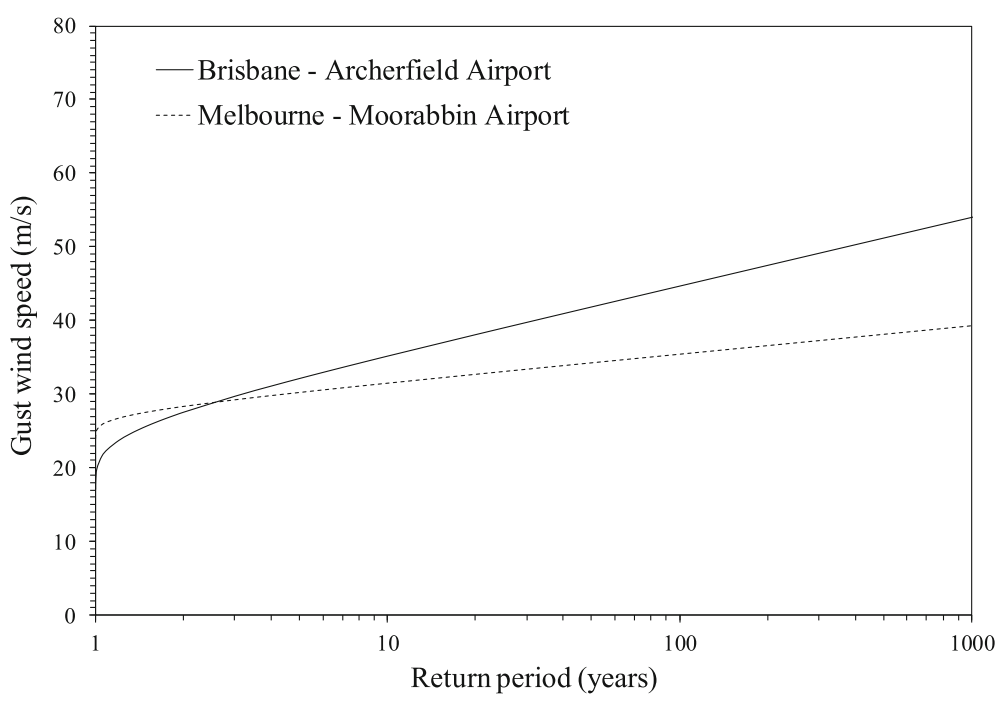

Fig. 2 Extreme gust wind speed corresponding to return periods 

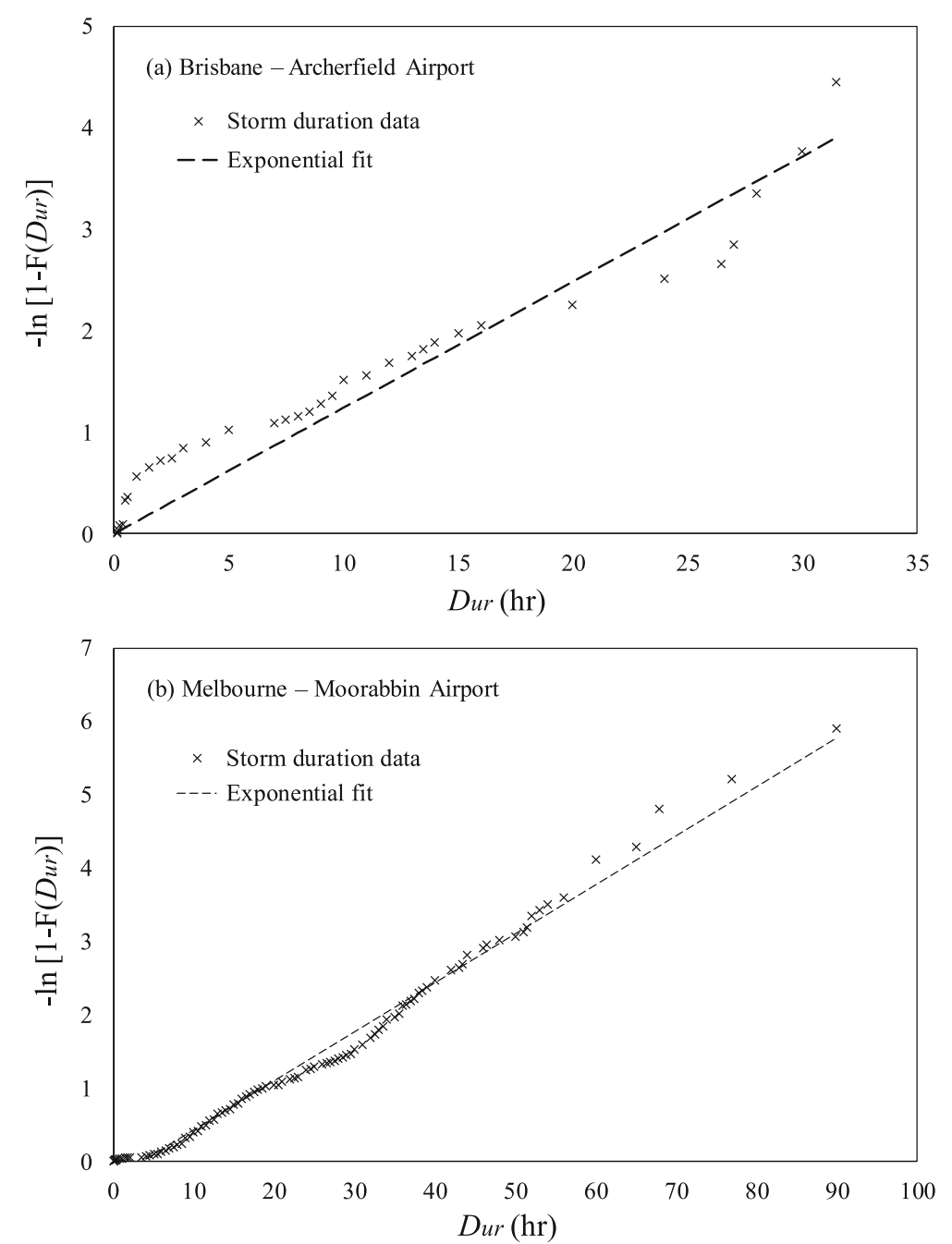

Fig. 3 Exponential probability plots for storm duration $D_{u r}$ [26]

is also involved in the projected magnitudes of change in wind speed due to the limitation of general circulation models [37]. To this end, a scenario-based analysis is conducted in this study to examine the climate change impacts on the cost-benefit analysis. While there may be scenarios with no change in climate, and even a reduced climate hazard, climate adaptation measures may still be recommended as there is no surety that current codes of practice are optimised for the current climate.

\section{Wind damage assessment Roof fragility}

A reliability-based fragility method developed by Qin \& Stewart [28] is used to assess the wind damage to metal roof cladding and timber roof trusses for the representative house described in Section "Representative contemporary house". The fragility of the roof system is defined as the extent of the roof sheeting loss and the roof truss failures as a function of the peak gust wind speed. Since the roof connections are generally the 'weakest links' of the roof system [13], the overloading of cladding-tobatten (CTB), batten-to-rafter/truss (BTR) and rafter/ truss-to-wall (RTW) connections (see Fig. 5) is considered as the limit states, the exceedance of which leads to the failure of roof cladding and trusses.

The uplift capacities for roof connections were modelled to follow a lognormal distribution [28]. For CTB and BTR connections, the uplift capacities were taken as the lower of the pull-out and pull-over strengths, and the uplift capacities for triple grip RTW connections were the peak loads in the force-displacement curves obtained from experiment tests [31]. The spatially varying wind uplift pressures acting on the roof surface were calculated from the peak gust wind speed and the wind loading parameters mainly including the terrain and height factor, shielding factor, wind directionality factor, external and internal pressure coefficients, etc. All the wind loading parameters were modelled as random variables with mean-to-nominal 

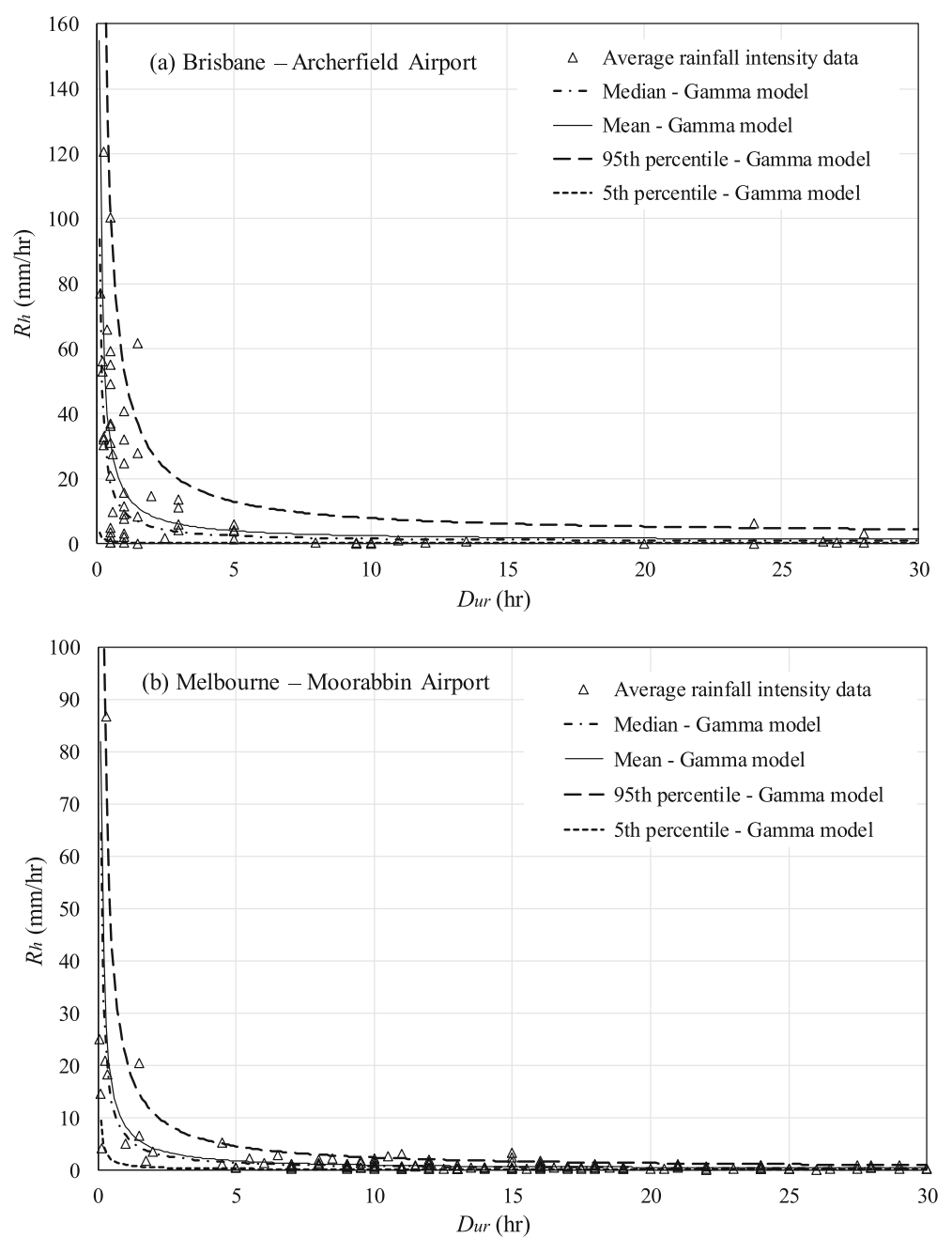

Fig. 4 Average rainfall intensity $R_{h}$ from the observed data and gamma regression model [26]

ratios and coefficient of variation (COV) values given in Qin \& Stewart [28]. The corresponding nominal values of these factors can be obtained from AS/NZS 1170.2 [4] for different site conditions. See Qin \& Stewart [28] for more details about roof connection resistances and the probabilistic wind loading modelling.

Two typical scenarios were assumed for the internal pressurization in the fragility analysis, i.e. (i) dominant openings existing on windward wall and (ii) without any wall openings. A Monte Carlo Simulation (MCS) analysis in conjunction with a finite element (FE) approach were

Table 1 Climate projections for extreme wind speed to 2090 under two $\mathrm{CO}_{2}$ emission scenarios

\begin{tabular}{|c|c|c|c|c|c|c|}
\hline & \multicolumn{3}{|l|}{ RCP4.5 } & \multicolumn{3}{|l|}{ RCP8.5 } \\
\hline & 10th & Median & 90th & 10th & Median & 90th \\
\hline Brisbane & $-8.0 \%$ & $-1.5 \%$ & $+1.0 \%$ & $-5.0 \%$ & $-2.0 \%$ & $\overline{+2.0 \%}$ \\
\hline Melbourne & $n / a$ & n/a & n/a & $-4.0 \%$ & $-1.0 \%$ & $+5.0 \%$ \\
\hline
\end{tabular}

employed to evaluate the wind fragility for roof cladding and trusses under the two wall opening scenarios, which enables the stochastic characterization of spatially varying wind uplift pressure, structural demands and resistances for roof connections, failure progression and load redistribution, and evolution of internal pressure with increasing sheeting loss. A total of 1646 CTB, 532 BTR and 38 RTW connections were involved in the MCS analysis and FE approach. The damage states for metal roof sheeting and timber roof trusses can then be obtained from the fragility assessment. The MCS and FE approach enables the development of two fragility curves: (i) the extent of roof sheeting loss, and (ii) proportion of roof truss failures. Refer to Qin \& Stewart [28] for more details about the MCS analysis, FE approach and fragility analysis.

The occurrence of construction defects reduces the wind resistance of housing components. Damage surveys have indicated that the commonly observed defects in residential construction increase the housing vulnerability 


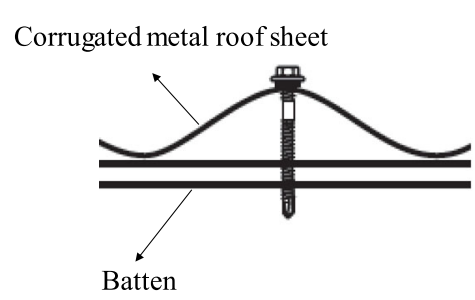

(a) CTB connector

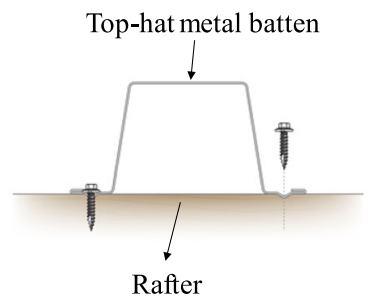

(b) BTR connector

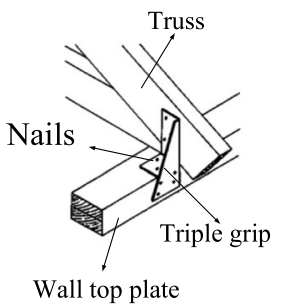

(c) RTW connector

Fig. 5 Roof connections used for the representative contemporary house

under wind hazard $[18,34]$. The construction defects are generally difficult to quantify due to the complex mechanism of human error and a lack of relevant data. Recently, Qin \& Stewart et al. [27] developed a probabilistic model for construction defects in roof connections, which systematically integrates the human reliability analysis method, engineering judgement and limited construction error data through a Bayesian approach. This construction defects model was further incorporated in the reliabilitybased fragility method to examine the effects of construction error on wind damage to the roof. This study adopts the construction defect model by Qin \& Stewart et al. [27] to further investigate the wind damage risks and the costeffectiveness of climate adaptation measures for the representative contemporary house with construction defects. The mean proportions of roof sheeting loss and roof truss failures produced by the fragility assessment for the Brisbane and Melbourne house with/without construction defects are shown in Fig. 6. It is indicated that, the effects of construction defects are considerable for the predicted roof cladding fragility, whereas for roof truss fragility, such effects are lower. Note that the RTW connections are different for houses with design wind classifications of N1, N2 and N3. Refer to Qin \& Stewart [27] for more details about the fragility analysis and construction defect model.

\section{Window damage}

The windward dominant openings and associated rainwater intrusion are considered to result from the breakage of windward windows by high wind pressure. Window failure caused by windborne debris is not considered in this study because windborne debris is less of a concern in non-cyclonic regions of Australia (AS/NZS 1170.22011). The wind pressure acting on the windward window $\left(W_{\text {win }}\right)$ is calculated based on the gust wind speed and the wind loading parameters (e.g. terrain and height factor, shielding factor, wind directionality factor, pressure coefficients, etc.). The ultimate strength $\left(R_{u l t}\right)$ and water penetration resistance $\left(R_{\text {water }}\right)$ of windows are assumed to follow a normal distribution [12] with the mean and COV estimated from the minimum test pressures specified in AS 2047 [2]. For more details, see Qin
\& Stewart [26] and Table 2. The limit states used for the windward window are shown in Table 3.

Although Australian standard AS 2047 [2] specifies the design window ratings for housing with different site conditions, the authors found that many window manufacturers do not provide detailed window ratings for their products. Window manufacturers are only required to publish energy data, but the structural performance data is non-mandatory in Australia. This may lead to construction error in practice that windows with unsatisfied or mislabeled window ratings are installed. The effect of this type of construction error in window installation on the cost-benefit analysis is examined in Section "Sensitivity analysis".

\section{Subsequent rainwater intrusion}

The volumetric rate of rainwater intrusion is mainly dependent on the wind speed, rainfall intensity, and damage states of the building envelope. A semi-empirical rainwater intrusion model [24, 40] is modified by Qin \& Stewart [26] and adapted to quantify the amount of rainwater intrusion into the damaged metal roof and windward windows. Empirical parameters involved in the rainwater intrusion model are used to account for the building disturbance to the oblique falling rain (i.e. effect of building geometry and aerodynamics), which are spatially variable, and estimated based on experimental tests and/or field monitoring data as well as engineering judgement.

The quantification of rainwater intrusion is also conducted under the two wall opening scenarios: i) presence of windward wall dominant openings, and ii) absence of any wall openings. For the windward dominant opening scenario, the main source of rainwater intrusion considered is water entering from roof and window breaches. For the scenario without any wall openings, rainwater is considered to enter through roof breaches and gaps around undamaged windward windows. The number and locations of failed roof sheets at a given wind speed obtained from the reliability-based fragility assessment described in Section "Roof fragility" are subsequent used in the MCS analysis by applying the semi-empirical rainwater intrusion model. The total volumetric rate of 

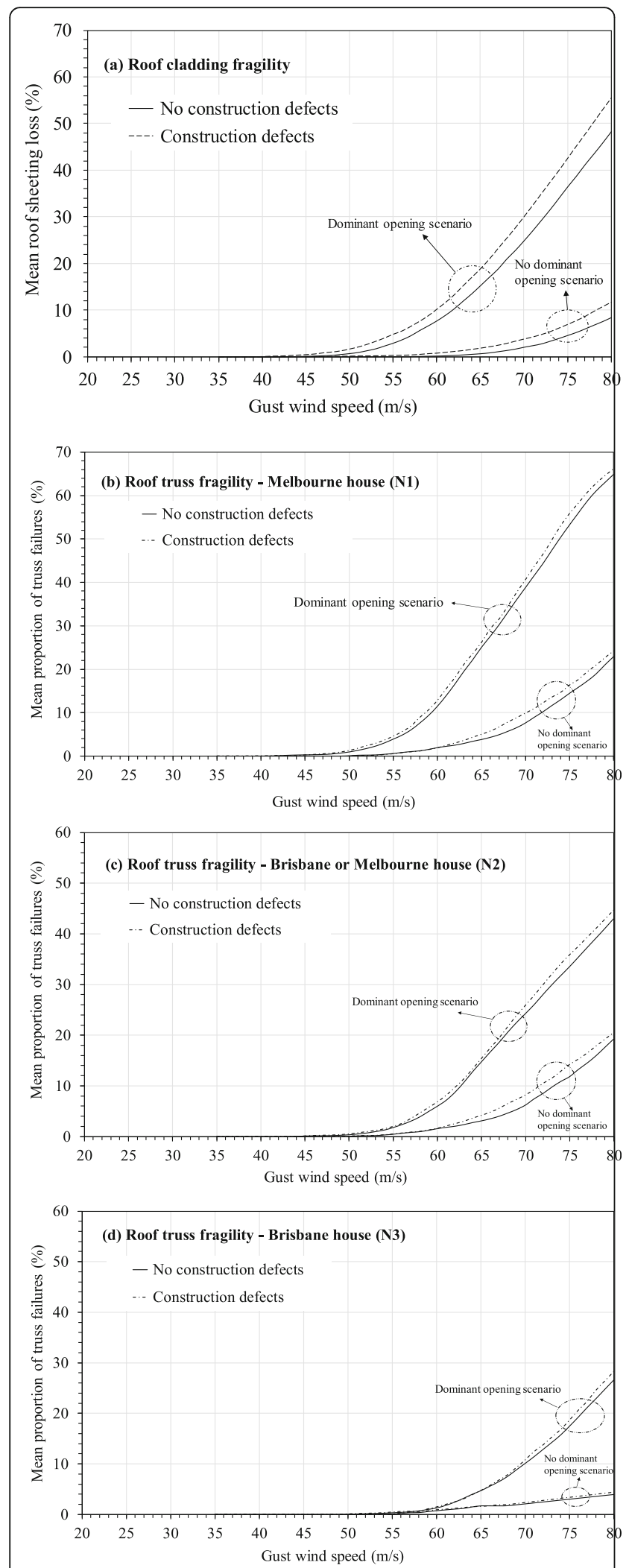

Fig. 6 Fragility for metal roof cladding and timber roof trusses with/ without construction defects
Table 2 Ultimate strength and water penetration resistance of windows

\begin{tabular}{lllllll}
\hline \multirow{2}{*}{$\begin{array}{l}\text { Window } \\
\text { rating }\end{array}$} & \multicolumn{2}{l}{$R_{\text {ult }}(\mathrm{Pa})$} & & \multicolumn{2}{l}{$R_{\text {water }}(\mathrm{Pa})$} & \multirow{2}{*}{$\begin{array}{l}\text { Distribution } \\
\text { type }\end{array}$} \\
& Mean & COV & & Mean & COV & \\
\hline N1 & 720 & 0.20 & & 180 & 0.20 & Normal \\
N2 & 1080 & 0.20 & & 180 & 0.20 & \\
N3 & 1680 & 0.20 & & 360 & 0.20 & \\
N4 & 2400 & 0.20 & & 360 & 0.20 & \\
\hline
\end{tabular}

rainwater intrusion can then be obtained. The volume of rainwater intrusion is calculated by the multiplication of the volumetric rate and the rainfall duration after wind damage. See Qin \& Stewart [26] for more details about the quantification of rainwater intrusion.

Construction defects in metal roof cladding can cause more roof sheeting loss, which may incur more rainwater intrusion through roof breaches. Figure 7 shows the mean volumetric rate of rainwater intrusion as a function of both the gust wind speed and rainfall intensity for the two wall opening scenarios with/without construction defects. As indicated in this figure, the mean rainwater intrusion rate increases with wind speed and rainfall intensity. The nonlinearity of rainwater intrusion with increasing wind speed is because there is more roof sheeting loss at a higher wind speed allowing for more water ingress. The rainwater intrusion rate is higher when construction defects are considered in the roof fragility assessment.

\section{Risk analysis \\ Loss estimation}

The loss estimation uses an assembly-based approach (e.g. $[11,12,25,38])$. The representative contemporary house is divided into components/subassemblies based on specific building details as shown in Table 4. The loss estimation takes into account the direct losses from wind damage to windward windows, metal roof cladding and timber roof framing, and the losses to building interior and contents caused by subsequent rainwater intrusion as well as the loss of use.

The losses are estimated in terms of cost ratios, which is defined as the ratio of the cost to complete the subassembly to the building value. The estimated total cost to build a new contemporary house with an approximate floor area of $150 \mathrm{~m}^{2}$ is $L_{\text {building }}=\$ 300,000$ Australian Dollars $[14,30]$. Based on cost data provided by Australian housing cost guides [29] and subjective judgement, the subassembly cost ratios for new construction are estimated for a representative contemporary house built to an average standard. The cost ratios are adjusted to account for the additional costs associated with removal, repair and remodelling of an existing house [12]. The adjusted cost ratios are also given in Table 4. The 
Table 3 Limit states for the windward window

\begin{tabular}{lll}
\hline Limit states & $\begin{array}{l}\text { Internal pressurisation } \\
\text { scenario }\end{array}$ & Water entry \\
\hline$W_{\text {win }} \geq R_{\text {ult }}$ & $\begin{array}{l}\text { Windward dominant } \\
\text { opening }\end{array}$ & $\begin{array}{l}\text { Via window } \\
\text { breakage }\end{array}$ \\
$W_{\text {win }} \geq R_{\text {water }} \cap$ & No dominant & Via small gaps \\
$W_{\text {win }}<R_{\text {ult }}$ & opening & around the window \\
$W_{\text {win }}<R_{\text {water }}$ & No dominant & No entry via \\
& opening & window \\
\hline
\end{tabular}

building interior herein includes internal finishes and fittings, mechanical and electrical systems. The cost ratio of contents is estimated to be $25 \%$ of the building value [1]

The empirical loss functions are given by Qin \& Stewart [26] to relate economic losses with the damage states of housing components, which are mainly based on engineering judgement and existing loss models given in HAZUS [12]. The losses to roof cladding and framing are directly expressed as a function of the roof damage states, whereas the building interior and contents losses are expressed as a function of the rainwater intrusion, which is indirectly related to roof cladding and window damage. The window losses are estimated based on the window damage model described in Section "Window damage". The loss function for loss of use is taken from HAZUS [12] which is a function of the expected total building loss. See Qin \& Stewart [26] for more details about the loss functions.

\section{Annual risk}

The annual risk (expressed as the expected loss) for a climate change scenario at time $t$ is

$$
\begin{aligned}
E_{\text {аппиа }}(t) & =\int_{0}^{\infty} \int_{0}^{\infty} \int_{0}^{\infty} f\left(R_{h}, t \mid v, D_{u r}\right) f(v, t) f\left(D_{u r}\right) \frac{1}{n_{d}(1+r)^{t}} \\
& \sum_{j=1}^{n_{d}}\left[\operatorname{Pr}\left(D S \mid v, R_{h}, D_{u r}\right) \sum_{i=1}^{n_{c}} \operatorname{Pr}\left(L_{i} \mid D S\right) L_{i}\right] d v d R_{h} d D_{u r}
\end{aligned}
$$

where $f(v, t)$ is the probability distribution of the annual maximum gust wind speed at time $t, f\left(R_{h}, t \mid v, D_{u r}\right)$ is the probability distribution of the average rainfall intensity of a severe windstorm corresponding to a given duration $D_{u r}$ at time $t, f\left(D_{u r}\right)$ is the probabilistic distribution of the windstorm duration which is assumed to be independent of climate change, $n_{d}=8$ is the number of cardinal wind directions considered in this study, $n_{\mathrm{c}}=6$ is the number of components/subassemblies considered in the loss estimation, $\operatorname{Pr}\left(D S \mid v, R_{h}, D_{u r}\right)$ is the probability of damage state (e.g. extent of roof damage, amount of rainwater intrusion) given the gust wind speed, rainfall intensity and storm duration, $\operatorname{Pr}\left(L_{i} \mid D S\right)$ is the loss likelihood for the $i^{\text {th }}$ component/subassembly given the damage state, $L_{i}$ is the maximum probable loss for the $i^{\text {th }}$ component/subassembly, and $r$ is the discount rate. As described in Section "Loss estimation", $L_{i}$ is the cost ratio for the $i^{\text {th }}$ component/subassembly given by Table 4 , and $\operatorname{Pr}\left(L_{i} \mid D S\right)$ is evaluated based on the empirical loss functions given the damage states of the roof and windows, and the amount of rainwater intrusion. More details can be found in Qin \& Stewart [26] and (Qin: Risk Assessment and Mitigation for Australian Contemporary Houses Subjected to Non-cyclonic Windstorms, under review). It is noted that Eq. (3) assumes that damage is caused by the largest wind event in any calendar year, which will slightly underestimate damage risks in the event of a lesser damaging windstorm in the same year.

The probabilistic risk assessment conducted using a MCS analysis consists of four major components, i.e. i) hazard modelling for extreme wind and associated rainfall, ii) reliability-based wind damage assessment for roof and windows, iii) evaluation of rainwater intrusion, and iv) loss estimation. Figure 8 shows an outline to illustrate the risk analysis method by Qin \& Stewart [26] to assess the annual expected economic losses for the representative contemporary house subjected to non-cyclonic windstorms. Table 5 shows the annual expected losses in the present year (normalized by the building value) for Brisbane and Melbourne houses with different design wind classifications with/without construction defects. The average days for loss of use and the expected losses for each housing component/subassembly are also given in this table. Table 5 suggests that losses to building interior and contents caused by rainwater intrusion is the major contributor to the annual expected loss. Houses in Brisbane are generally subjected to higher losses than houses in Melbourne because the extreme wind speed and rainfall intensity are higher in Brisbane as shown in Section "Hazard modelling and climate change impacts". The annual expected losses for houses in Brisbane with construction defects are considerably higher than that without considering construction defects, whereas the effect of construction defects on the calculated risk is slight for Melbourne houses. This is expected because the metal roof sheeting loss is negligible for the Melbourne house even with the consideration of construction defects, and there is not much increase in subsequent rainwater intrusion from roof breaches.

\section{Climate adaptation \\ Adaptation measures}

The climate adaptation measures proposed in this study mainly aim to reduce the rainwater damage to building interior and contents. The fragility and risk analysis show that wind damage to roof cladding is highly likely to occur for the representative contemporary house in Brisbane. The failure of metal roof sheets can further incur rainwater intrusion through the roof breaches, 

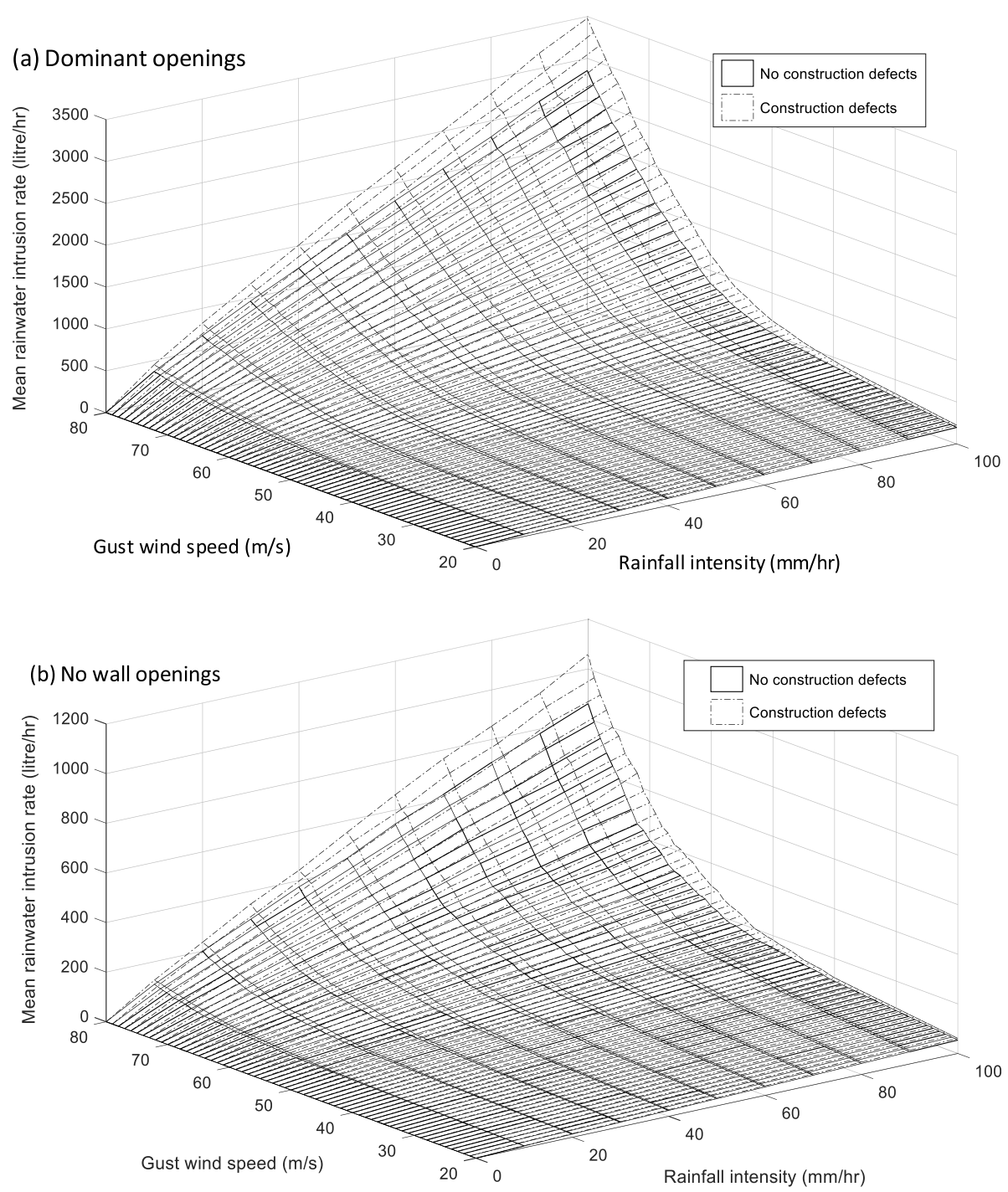

Fig. 7 Mean volumetric rate of rainwater intrusion with/without construction defects

Table 4 Subassembly cost ratios for the representative contemporary house

\begin{tabular}{|c|c|c|c|c|}
\hline Subassembly & & Description & Cost ratio & Adjusted cost ratio \\
\hline \multirow[t]{2}{*}{ Roof } & Roof cladding & $\begin{array}{l}\text { Mainly including corrugated metal roof sheets, } \\
\text { metal top-hat battens and insulation }\end{array}$ & $4.1 \%$ & $5.4 \%$ \\
\hline & Roof framing & Timber trusses, rafters, ceiling joists, fixings, etc. & $15.9 \%$ & $20.9 \%$ \\
\hline Windward Windows & & Single glazed, aluminum sliding or awning windows & $0.8 \%$ & $1.0 \%$ \\
\hline \multirow[t]{4}{*}{ Internal finishes, fittings } & Wall & $\begin{array}{l}\text { Mostly plasterboard, also include ceramic tiles and } \\
\text { painting }\end{array}$ & $6.8 \%$ & $51.2 \%$ (building interior) \\
\hline & Floor & Mixed use of timber, carpet and ceramic tiles & $3.5 \%$ & \\
\hline & Ceiling & Mostly plasterboard, also including painting & $4.7 \%$ & \\
\hline & Fittings and fixtures & $\begin{array}{l}\text { Built-in wardrobes/cupboards, kitchen units, bathroom } \\
\text { suites, shelving, internal doors, etc. }\end{array}$ & $10.0 \%$ & \\
\hline Mechanical & & Air conditioning, heaters, ventilation, etc. & $10.0 \%$ & \\
\hline Electrical & & Lighting, conduits, cables, etc. & $4.0 \%$ & \\
\hline Other & & $\begin{array}{l}\text { Site preparation, foundation, wall framing, other } \\
\text { fenestrations, plumbing, etc. }\end{array}$ & $37.0 \%$ & $n / a$ \\
\hline
\end{tabular}




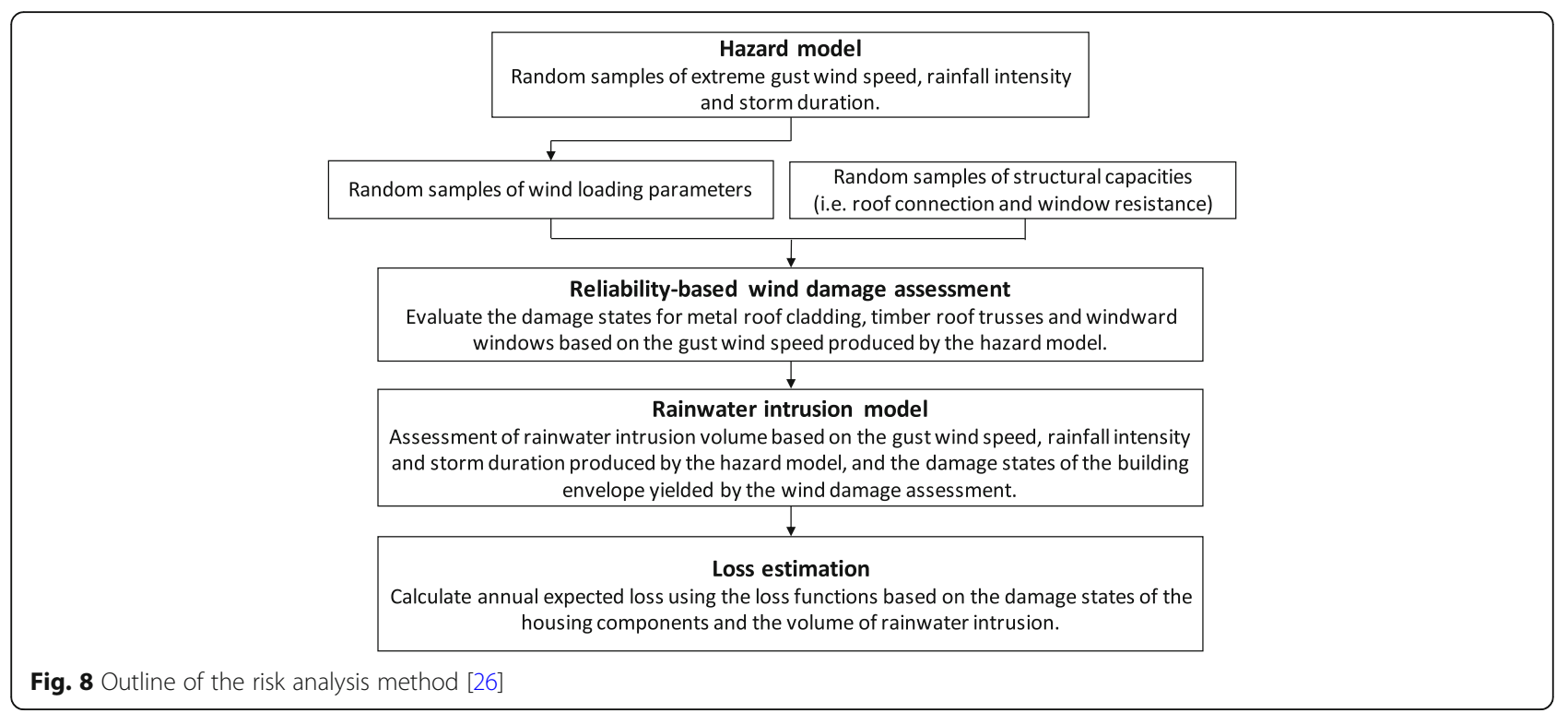

though the direct loss from roof cladding damage is limited due to a small cost ratio as shown in Table 4. Window breakage by high wind pressure creates windward dominant openings, which allows for more rainwater intrusion and roof damage due to significantly increased internal pressure. Rainwater intrusion via small gaps around undamaged windows may also occur when the water penetration resistance of window is exceeded. Strengthening roof cladding and windows not only decreases the direct losses from wind damage to the building envelope, but also reduce the amount of rainwater intrusion. In addition to reinforcing the building envelope, the use of water-resistant materials for building interior can also reduce the rainwater damage.

To this end, four adaptation measures are proposed herein: (i) increase of uplift capacities for cladding-to- batten (CTB) connections (RF), (ii) protection of windows by shutters (WS), (iii) improvement of window resistances (WR), and (iv) use of water-resistant materials for ceiling and internal wall finishes (IW). The fragility analysis reveals that the damage proportions of BTR and RTW connections are considerably less than the failures of $\mathrm{CTB}$ connections [28], and hence RF is to strengthen CTB connections by (i) increasing the base metal thickness (BMT) of metal roof cladding from $0.42 \mathrm{~mm}$ to $0.48 \mathrm{~mm}$, and (ii) upgrading the screw fastener for CTB connections from M6-11 (diameter of $6.0 \mathrm{~mm}$ and 11 threads per inch) to 14-12 (diameter of $6.3 \mathrm{~mm}$ and 12 threads per inch). This improves the mean pull-over and pull-out capacities of CTB connections by $25 \%$ and $7 \%$, respectively. In WS, cyclone-rated steel roller shutters tested for wind pressure up to $2500 \mathrm{~Pa}$ are used. The shutter strength against wind

Table 5 Annual risk for the representative contemporary house

\begin{tabular}{|c|c|c|c|c|c|c|c|c|}
\hline & \multirow{2}{*}{$\begin{array}{l}\text { Design } \\
\text { wind } \\
\text { classification }\end{array}$} & \multicolumn{6}{|c|}{ Annual expected losses (\%) } & \multirow[b]{2}{*}{ Loss of use (days) } \\
\hline & & Roof clad & Roof framing & Windward window & Building interior & Contents & Total & \\
\hline \multicolumn{9}{|l|}{$\begin{array}{l}\text { (a) No construction } \\
\text { defects }\end{array}$} \\
\hline \multirow[t]{2}{*}{ Brisbane house } & N2 & 0.004 & 0.003 & 0.003 & 0.069 & 0.030 & 0.109 & 0.22 \\
\hline & N3 & 0.006 & 0.002 & 0.001 & 0.053 & 0.023 & 0.085 & 0.17 \\
\hline \multirow[t]{2}{*}{ Melbourne house } & N1 & 0.000 & 0.000 & 0.000 & 0.024 & 0.011 & 0.035 & 0.04 \\
\hline & N2 & 0.000 & 0.000 & 0.000 & 0.032 & 0.014 & 0.046 & 0.06 \\
\hline \multicolumn{9}{|l|}{$\begin{array}{l}\text { (b) With construction } \\
\text { defects }\end{array}$} \\
\hline \multirow[t]{2}{*}{ Brisbane house } & N2 & 0.005 & 0.003 & 0.003 & 0.085 & 0.037 & 0.133 & 0.29 \\
\hline & N3 & 0.008 & 0.002 & 0.001 & 0.066 & 0.028 & 0.105 & 0.24 \\
\hline \multirow[t]{2}{*}{ Melbourne house } & N1 & 0.000 & 0.000 & 0.000 & 0.026 & 0.011 & 0.037 & 0.04 \\
\hline & N2 & 0.000 & 0.000 & 0.000 & 0.034 & 0.015 & 0.049 & 0.06 \\
\hline
\end{tabular}


pressure is assumed to follow a normal distribution with a mean of $3000 \mathrm{~Pa}$ and a COV of 0.20 , which implies that $20 \%$ of the shutters cannot satisfy the test pressure to account for the variance of quality in manufacture and installation. A triangular distribution with a lower bound of $50 \%$ and an upper bound of $100 \%$ as shown in Fig. 9 is assumed for the reduction of wind pressure and winddriven rain on windows due to the installation of shutters, if not damaged. HAZUS [12] assumes the reduction is $50 \%$ which is considered as a lower bound for a cyclonerated roller shutter. Window resistances may be increased by using a higher window rating (i.e. $\mathrm{N} 1$ to $\mathrm{N} 2, \mathrm{~N} 2$ to $\mathrm{N} 3$ and N3 to N4). Note that improving window ratings does not necessarily increase the water penetration resistances of windows as shown in Table 2. By adding some additives in manufacture, the water absorption rate of plasterboard can be reduced. Gypsum plasterboard with specified water-resistant grade given by AS/NZS 2588 [5] may be used as the internal linings for ceiling and wall. Waterresistant gypsum plasterboard is required to have an average water absorption of less than $5 \%$ of self-weight after two-hour immersion under a minimum of $25 \mathrm{~mm}$ of water [5], and a triangular probability distribution given by Fig. 10 is assumed to model the reduction of rainwater damage to internal linings. The internal linings (i.e. ceiling and wall finishes) consist of $30 \%$ of the building interior value as shown in Table 4.

The proposed climate adaptation measures are summarized in Table 6. The adaptation cost (normalized by building value) and the improved performance due to the adaptation measure (i.e. benefit in Table 6) are also shown in Table 6. The adaptation measures applied at the initial design and construction are RF, WR and IW, whereas window shutters (WS) can be installed at any time during the service life to retrofit an existing house. The adaptation cost is the additional money spent on the adaptation measure, which is considered as a one-off expense. The adaptation costs presented in Table 6 are estimated from an Australian housing construction cost guide [29]. The

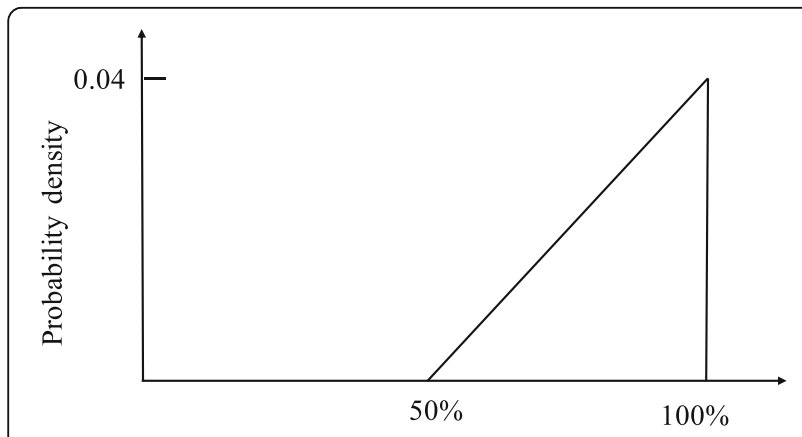

Reduction of wind pressure and driving rain

Fig. 9 Reduction of wind pressure and wind-driven rain on windward windows due to shutters

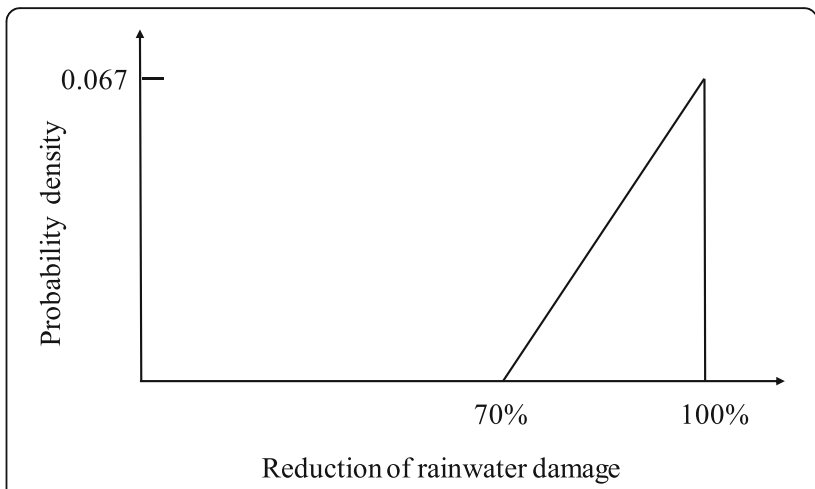

Fig. 10 Reduction of rainwater damage to internal linings by using water-resistant plasterboard

effect of variations in adaptation costs on the cost-benefit analysis is examined through a break-even analysis in Section "Evaluation of cost-effectiveness".

\section{Cost-benefit analysis results Cumulative risks}

The cumulative expected loss (or risks) over the 50-year service life of the house from 2020 to 2070 is given by

$$
E(L)=\sum_{t=2020}^{2070} E_{\text {annual }}(t)
$$

where $E_{\text {annual }}(t)$ is the annual risk at time $t$, which is influenced by the climate change and discount rate. In this study, the cumulative economic risks are presented in 2020 Australian dollars and a discount rate of $r=4 \%$ is used [38]. A sensitivity analysis is conducted in Section "Sensitivity analysis" using different discount rates.

Figure 11 shows the cumulative expected losses to 2070 considering construction defects. A constant climate is assumed in this section (i.e. no climate change impacts on wind and rainfall), and the climate change impacts are examined in Section "Climate change impacts". The cumulative expected losses to 2070 and risk reductions (shown in bracket) provided by the adaptation measures are shown in Table 7. In this section, it is assumed that the adaptation measure WS is applied at the new construction (i.e. Year 2020) to maximise its benefits (i.e. risk reduction). Figure 11 and Table 7 suggest that installing window shutters (WS) is the most effective adaptation measure that provides over 95\% risk reduction. Strengthening roof connections (RF) provides up to $8 \%$ risk reduction for Brisbane houses but it is not effective for Melbourne houses, which is expected as roof failure is rare and most losses for houses in Melbourne are attributed to rainwater intrusion through windward windows. Improving window ratings (WR) offers more risk reduction when both the ultimate strength and water penetration resistance of windows are increased (i.e. N2 to N3), whereas less risk 
Table 6 Climate adaptation measures for contemporary housing

\begin{tabular}{|c|c|c|c|c|}
\hline $\begin{array}{l}\text { Housing } \\
\text { component }\end{array}$ & Adaptation measure & Description & $\begin{array}{l}\text { Adaptation } \\
\text { cost }\end{array}$ & Benefit \\
\hline Roof cladding & $\begin{array}{l}\text { RF. Strengthen CTB } \\
\text { connections }\end{array}$ & $\begin{array}{l}\text { Increase BMT of metal roof sheets } \\
\text { from } 0.42 \text { to } 0.48 \mathrm{~mm} \text {, and upgrade } \\
\text { the screw fastener from M6-11 to } 14-12 \text {. }\end{array}$ & $0.7 \%$ & $\begin{array}{l}\text { Improve the uplift capacities of CTB connections } \\
\text { with the mean pull-over and pull-out capacity } \\
\text { increased by } 25 \% \text { and } 7 \% \text { respectively. }\end{array}$ \\
\hline \multirow[t]{2}{*}{ Window } & WS. Install shutters & $\begin{array}{l}\text { Cyclone-rated steel roller shutters } \\
\text { tested for wind pressure up to } 2500 \mathrm{~Pa} \text {. }\end{array}$ & $2.0 \%$ & $\begin{array}{l}\text { Reduce wind pressure and the amount of } \\
\text { wind-driven rain acting on windows as } \\
\text { shown in Fig. 9, and hence decrease the } \\
\text { probability of windward dominant openings. }\end{array}$ \\
\hline & $\begin{array}{l}\text { WR. Higher window } \\
\text { rating }\end{array}$ & $\begin{array}{l}\text { Increase the window rating to a } \\
\text { higher level } \\
\text { (e.g. N2 to N3). }\end{array}$ & $0.4 \%$ & $\begin{array}{l}\text { Increase the ultimate strength and water } \\
\text { penetration resistance of windows } \\
\text { according to Table } 2 \text {. }\end{array}$ \\
\hline Building interior & $\begin{array}{l}\text { IW. Water resistant } \\
\text { materials }\end{array}$ & $\begin{array}{l}\text { Use water-resistant plasterboard } \\
\text { for ceiling and internal wall finishes. }\end{array}$ & $1.0 \%$ & $\begin{array}{l}\text { Improve water resistance of building } \\
\text { interior and reduce rainwater damage } \\
\text { as shown in Fig. } 10 .\end{array}$ \\
\hline
\end{tabular}

reduction is achieved if only the ultimate strength is increased (i.e. N1 to N2, N3 to N4). Using water-resistant materials for internal linings (IW) is generally effective, and provides about $20 \%$ risk reduction. As expected, considerably higher cumulative expected losses are predicted for houses in Brisbane with construction defects compared to those without construction defects, whereas the effect of construction defects on cumulative risks for Melbourne houses is slight.

\section{Evaluation of cost-effectiveness}

The cost-benefit analysis is conducted using the annual and cumulative expected losses evaluated based on the PRA method by Qin \& Stewart [28] as described in Section "Risk analysis", which provides a risk-based decision support tool for the selection of cost-effective climate adaptation measures for houses subjected to non-cyclonic windstorms. The procedures for the cost-benefit analysis are summarized as:

(i) Calculate the annual expected loss in year $t$ for the considered house without adaptation using the PRA method described in Section "Risk analysis", and then calculate the cumulative expected loss for the 50-year building service life using Eq. (4);

(ii) Calculate the annual expected loss in year $t$ for the considered house with a given adaptation measure using the PRA method described in Section "Risk analysis", and then calculate the cumulative expected loss for the 50-year building service life using Eq. (4);

(iii) Calculate the reduced cumulative expected loss due to the adaptation measure, i.e. $E(L) \Delta R$ in Eq. (2);

(iv) Implement (ii) and (iii) for all considered adaptation measures, and then calculate the mean NPVs corresponding to these adaptation measures using Eq. (2); (v) Decision-making based on the mean NPVs corresponding to different adaptation measures. Adaptation measures with the mean NPV greater than zero are deemed as cost-effective, and those with a higher mean NPV is preferred by assuming a risk neutral decision-maker whose primary goal is economic efficiency.

Table 8 shows the mean NPVs to 2070 for the representative contemporary house with/without construction defects and no climate change is assumed. Table 8 suggests that, in most cases, the mean NPVs of adaptation measures with the consideration of construction defects are higher than those without considering construction defects. This is expected because construction defects result in higher cumulative risks and a specific adaptation measure can generally offer more reduction in ecnomic losses (i.e. $E(L) \Delta R$ ) at a given adaptation cost. For the Brisbane house with a design wind classification of N2, the adaptation measures yielding a positive mean NPV are WS and WR. No adaptation measure is cost-effective for the Brisbane house with a design wind classification of N3 without considering construction defects, however, WS turns to a positive mean NPV when construction defects are taken into account. This illustrates the effect of construction defects on the cost-benefit analysis. None of the adaptation measures may be recommended for the Melbourne house with a design wind classification of $\mathrm{N} 1$ as the corresponding mean NPVs are negative. Table 8 also shows that WR is the only costeffective adaptation measure for the Melbourne house with a design wind classification of $\mathrm{N} 2$.

The adaptation costs given in Table 6 are estimated according to the average cost data given by Australian housing construction cost guide [29]. However, the costs may vary among different locations, contractors and labourers. A break-even analysis is thus conducted to calculate the maximum adaptation cost that enables the mean NPV to be zero with the consideration of construction defects, see 

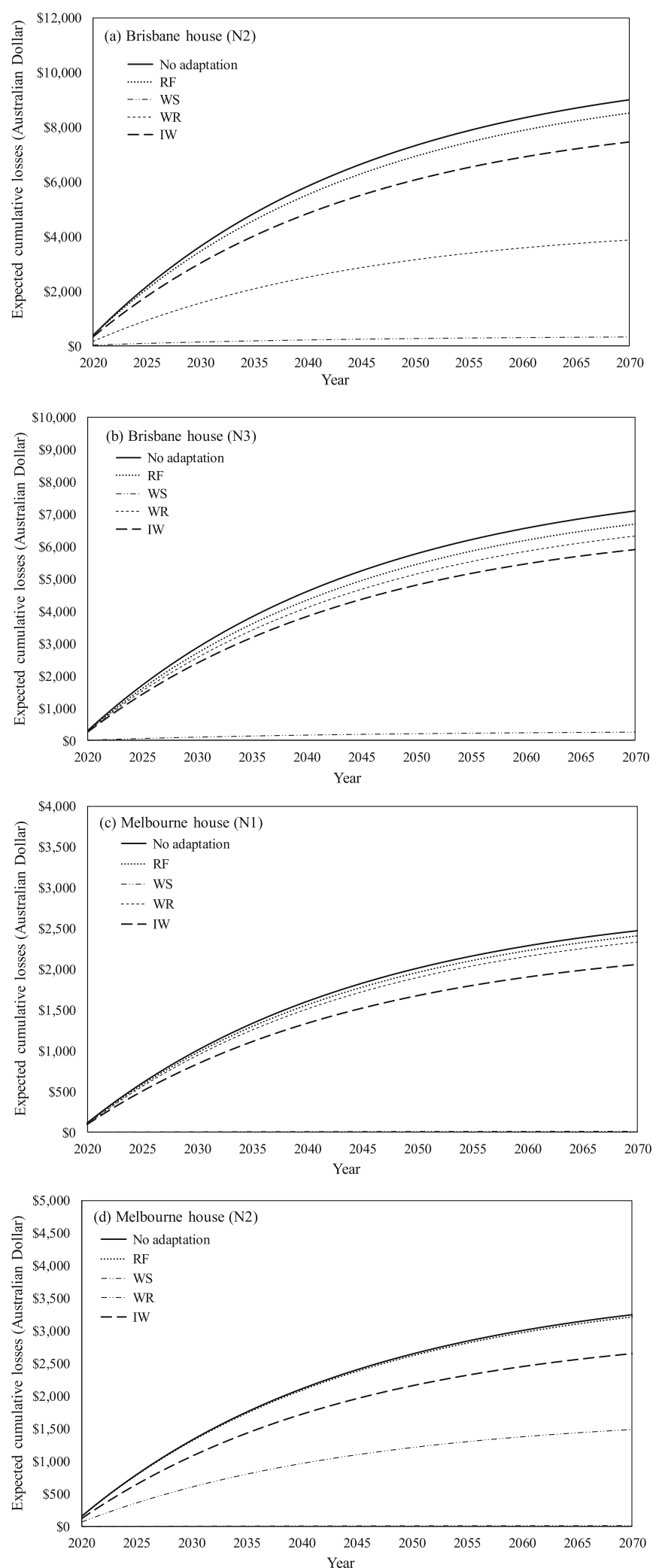

Fig. 11 Cumulative expected losses for houses with construction defects and no climate change 
Table 7 Cumulative expected losses to 2070 with no climate change

\begin{tabular}{|c|c|c|c|c|c|c|}
\hline & \multirow{2}{*}{$\begin{array}{l}\text { Design } \\
\text { wind } \\
\text { classification }\end{array}$} & \multicolumn{5}{|c|}{ Cumulative expected losses $E(L)$ and risk reduction $\Delta R$} \\
\hline & & No adaptation & RF & WS & WR & IW \\
\hline \multicolumn{7}{|c|}{$\begin{array}{l}\text { (a) No construction } \\
\text { defects }\end{array}$} \\
\hline \multirow[t]{2}{*}{ Brisbane } & N2 & $\$ 7364$ & $\$ 6807(8 \%)$ & $\$ 292(96 \%)$ & $\$ 3260(56 \%)$ & $\$ 5870(20 \%)$ \\
\hline & N3 & $\$ 5738$ & $\$ 5387(6 \%)$ & \$191 (97\%) & $\$ 4997(13 \%)$ & $\$ 4905(15 \%)$ \\
\hline \multirow[t]{2}{*}{ Melbourne } & N1 & $\$ 2381$ & $\$ 2270(5 \%)$ & $\$ 8(99 \%)$ & $\$ 2153(10 \%)$ & $\$ 2009(16 \%)$ \\
\hline & N2 & $\$ 3069$ & $\$ 2926(5 \%)$ & $\$ 10(99 \%)$ & $\$ 1344(56 \%)$ & $\$ 2567(16 \%)$ \\
\hline \multicolumn{7}{|c|}{$\begin{array}{l}\text { (b) With construction } \\
\text { defects }\end{array}$} \\
\hline \multirow[t]{2}{*}{ Brisbane } & N2 & $\$ 8995$ & $\$ 8512(5 \%)$ & $\$ 337(96 \%)$ & $\$ 3875(57 \%)$ & $\$ 7456(17 \%)$ \\
\hline & N3 & $\$ 7106$ & $\$ 6707$ (6\%) & \$267 (96\%) & $\$ 6335$ (11\%) & \$5904 (17\%) \\
\hline \multirow[t]{2}{*}{ Melbourne } & N1 & $\$ 2475$ & $\$ 2409(3 \%)$ & $\$ 8(99 \%)$ & $\$ 2331(10 \%)$ & $\$ 2062(17 \%)$ \\
\hline & N2 & $\$ 3251$ & $\$ 3162(3 \%)$ & \$12 (99\%) & \$1481 (55\%) & $\$ 2648(18 \%)$ \\
\hline
\end{tabular}

Table 9. It is indicated from Table 9 that an adaptation measure may turn to be cost-effective with reasonable discounts on the cost given by Table 6. For example, only a $13 \%$ discount on the adaptation cost makes WR costeffective for the Brisbane house with a design wind classification of N3, whereas a $50 \%$ reduction in cost is needed to enable IW to be cost-effective for the Brisbane house with a design wind classification of N2. A few adaptation measures can remain cost-effective even with significantly increased costs. For example, WR is still cost-effective for the Brisbane house with a design wind classification of $\mathrm{N} 2$, if the anticipated cost of WR given by Table 6 increases by $300 \%$.

\section{Climate change impacts}

A scenario-based analysis is conducted to examine the costeffectiveness of the climate adaptation measures under a changing climate. The median, 10th and 90th percentile

Table 8 Mean NPVs to 2070 with no climate change

\begin{tabular}{|c|c|c|c|c|c|}
\hline & \multirow{2}{*}{$\begin{array}{l}\text { Design } \\
\text { wind } \\
\text { classification }\end{array}$} & \multicolumn{4}{|c|}{ Mean NPV } \\
\hline & & RF & WS & WR & IW \\
\hline \multicolumn{6}{|c|}{$\begin{array}{l}\text { (a) No construction } \\
\text { defects }\end{array}$} \\
\hline \multirow[t]{2}{*}{ Brisbane } & N2 & $-\$ 1543$ & $\$ 1072$ & $\$ 2904$ & $-\$ 1506$ \\
\hline & N3 & $-\$ 1749$ & $-\$ 453$ & $-\$ 460$ & $-\$ 2167$ \\
\hline \multirow[t]{2}{*}{ Melbourne } & $\mathrm{N} 1$ & $-\$ 1989$ & $-\$ 3628$ & $-\$ 972$ & $-\$ 2629$ \\
\hline & N2 & $-\$ 1957$ & $-\$ 2941$ & $\$ 525$ & $-\$ 2499$ \\
\hline \multicolumn{6}{|c|}{$\begin{array}{l}\text { (b) With construction } \\
\text { defects }\end{array}$} \\
\hline \multirow[t]{2}{*}{ Brisbane } & N2 & $-\$ 1618$ & $\$ 2657$ & $\$ 3920$ & $-\$ 1461$ \\
\hline & N3 & $-\$ 1701$ & $\$ 839$ & $-\$ 429$ & $-\$ 1798$ \\
\hline \multirow[t]{2}{*}{ Melbourne } & $\mathrm{N} 1$ & $-\$ 2034$ & $-\$ 3533$ & $-\$ 955$ & $-\$ 2586$ \\
\hline & N2 & $-\$ 2011$ & $-\$ 2761$ & $\$ 570$ & $-\$ 2398$ \\
\hline
\end{tabular}

projections for wind speed change under RCP 4.5 and RCP 8.5 as shown in Table 1 are adopted, and the changes in rainfall intensity to 2090 conditional on an extreme wind climate scenario are assumed to be $-20 \%,-10 \%, 0 \%,+10 \%$ and $+20 \%$. Information is scarce to non-existent on timedependent changes in extreme wind speed and associated rainfall for Australia. A time-dependent linear change [38] is then assumed for both wind speed and rainfall intensity. The mean NPVs for different adaptation measures to 2070 with the consideration of construction defects and climate change impacts are shown in Fig. 12. The mean NPVs in the figure are for Brisbane and Melbourne houses with a design wind classification of $\mathrm{N} 2$ as they are more vulnerable than N1 and N3 houses. The error bars in Fig. 12 represent the 10th and 90th percentile projections for wind speed change under RCP 4.5 and RCP 8.5. It is observed that, in general, the larger the wind speed and the associated rainfall intensity in a future climate, the higher the mean NPVs produced by the climate adaptation measures. Climate change tends to have higher influences on the cost-effectiveness of adaptation measures applied to houses in Brisbane.

Installing window shutters (WS) and increasing window ratings (WR) remain cost-effective for the Brisbane house (N2), and WR is cost-effective for the Melbourne house (N2) under all the considered climate scenarios.

Table 9 Break-even adaptation costs (normalized by the building value) for different climate adaptation measures to be cost-effective (with construction defects)

\begin{tabular}{llllll}
\hline & $\begin{array}{l}\text { Design } \\
\text { wind } \\
\text { classification }\end{array}$ & \multicolumn{4}{l}{ Break-even cost } \\
\cline { 3 - 6 } BF & WS & WR & IW \\
\hline Brisbane & N2 & $0.16 \%$ & $2.89 \%$ & $1.71 \%$ & $0.51 \%$ \\
& N3 & $0.13 \%$ & $2.28 \%$ & $0.26 \%$ & $0.40 \%$ \\
& N1 & $0.03 \%$ & $0.82 \%$ & $0.08 \%$ & $0.14 \%$ \\
& N2 & $0.03 \%$ & $1.08 \%$ & $0.59 \%$ & $0.20 \%$ \\
\hline
\end{tabular}




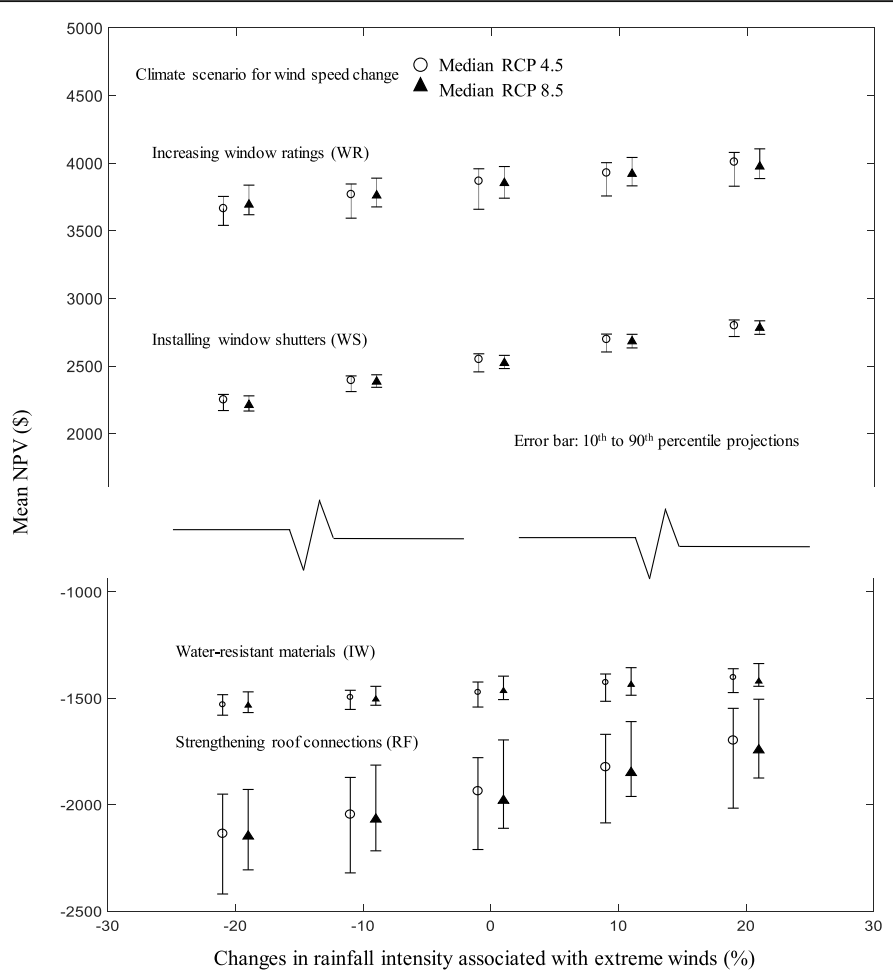

(a) Brisbane house N2

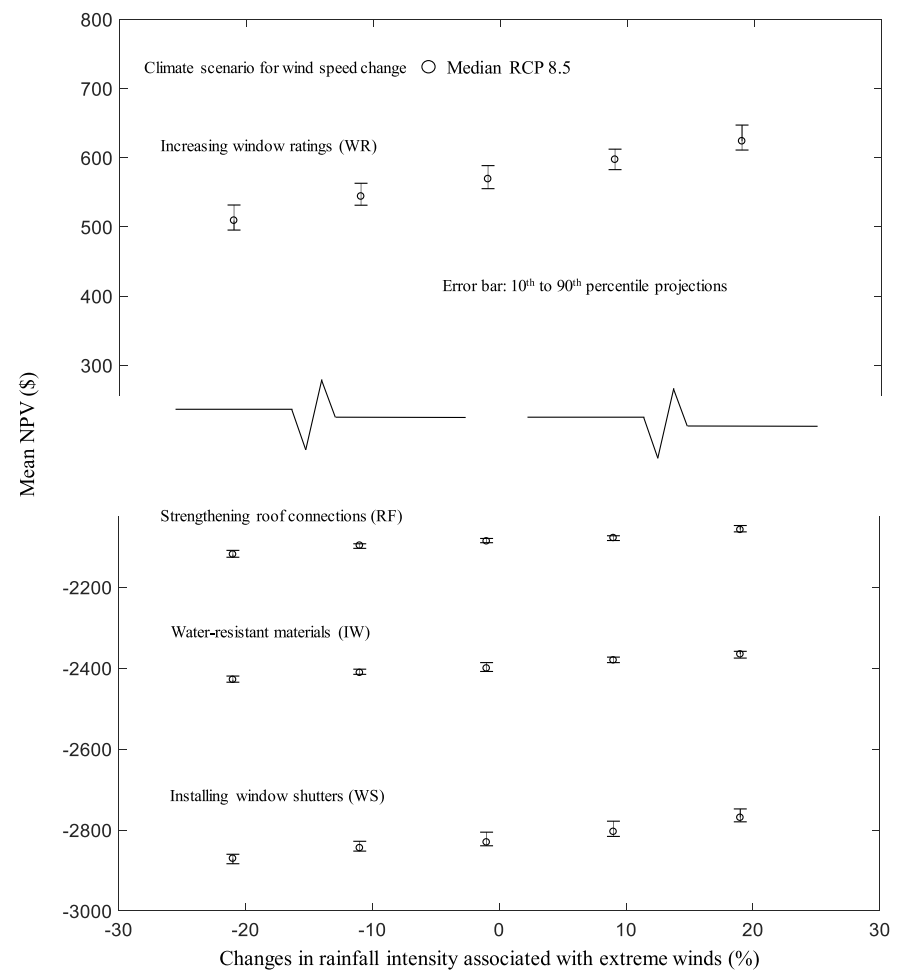

(b) Melbourne house N2

Fig. 12 Climate change impacts on mean NPVs for different climate adaptation measures 


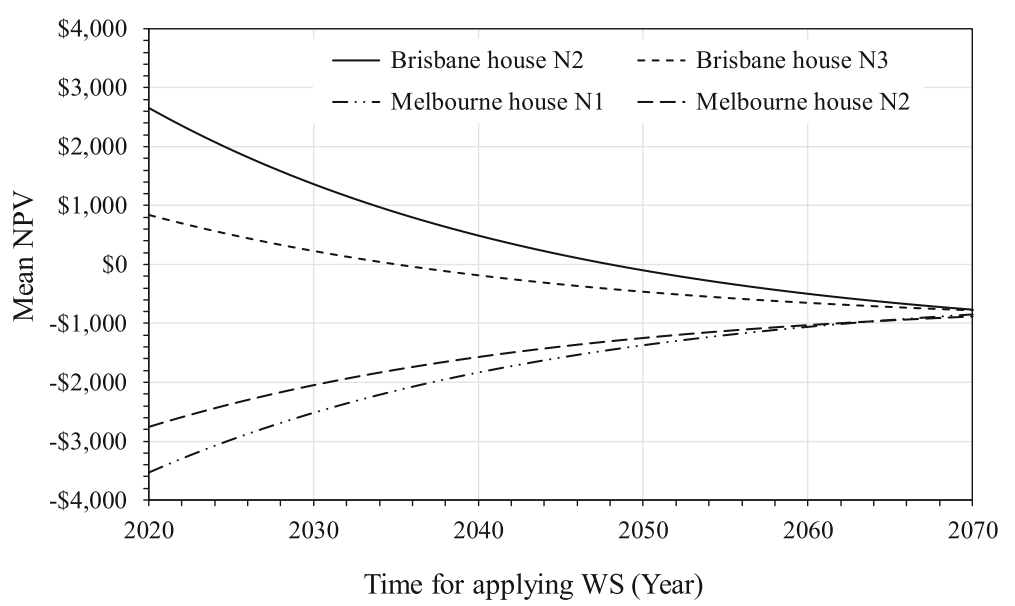

Fig. 13 Effect of the time for installing window shutters (WS) on the mean NPV

For the most adverse climate scenario considered in this study (i.e. 90th percentile projection for extreme wind speed under RCP 8.5 and a $20 \%$ increase in rainfall intensity), the mean NPVs increase by approximately $15 \%$ and $10 \%$ respectively for WS and WR compared to the scenario with no climate change. Therefore, the effect of climate change on the cost-benefit analysis is not significant. Strengthening roof connections (RF) and using water-resistant materials (IW) are not cost-effective under all the considered climate change scenarios. In addition, the co-benefits ( $\Delta B$ given in Eq. (2)) associated with RF and IW are negligible, whereas considerable cobenefits exist for WS and WR. Using a higher window rating (WR) may provide energy efficiency due to increased glass thickness. Window shutters (WS) can offer more co-benefits such as noise reduction, prevention of heat loss, light control and home security. Although the mean NPV of WR is higher than that corresponding to WS for the Brisbane house (N2) under a changing climate, WS is still a competitive option for climate adaptation due to considerable co-benefits. In terms of implications for insurance premium, an insurer may offer incentives by a discount in annual insurance premium for homeowners who decide to retrofit their houses by installing window shutters.

\section{Sensitivity analysis}

The adaptation measure WS is considered as a retrofit that can be applied at any year during the service life. Figure 13 shows the mean NPV to 2070 for houses with no climate change when installing window shutters at different points in time. It is indicated that WS is costeffective for houses in Brisbane if applied no later than 2048 for N2 houses and 2035 for N3 houses. The mean NPVs to 2070 increase for houses in Melbourne if window shutters are installed in a later year.
Two discount rates (i.e. 2\% and 7\%) are further adopted in the cost-benefit analysis, and the corresponding mean NPVs with the consideration of construction defects and no climate change are given in Table 10. As expected, the mean NPV increases for a lower discount rate, and decreases for a higher discount rate. Installing window shutters (WS) for Brisbane houses with design wind classifications of $\mathrm{N} 2$ and $\mathrm{N} 3$ is no longer cost-effective under a discount rate of $7 \%$. Increasing window ratings (WR) for the Brisbane house with a design wind classification of N3 turns to be costeffective under a discount rate of $2 \%$.

The construction error of using mislabelled windows as described in Section "Window damage" is not considered in the cost-benefit analysis described above. A scenario-based approach is used herein to examine the effects of mislabelled windows. It is assumed that N1rated windows are incorrectly installed on Brisbane and Melbourne houses with a design wind classification of $\mathrm{N} 2$, and N2-rated windows are incorrectly installed on Brisbane houses with a design wind classification of N3.

Table 10 The effect of discount rate on mean NPV

\begin{tabular}{clllll}
\hline \multicolumn{5}{c}{$\begin{array}{l}\text { Design } \\
\text { wind } \\
\text { classification }\end{array}$} & \multicolumn{4}{c}{ Mean NPV } \\
\cline { 3 - 6 } (a) Discount rate of 2\% & RF & WR & IW \\
Brisbane & N2 & $-\$ 1404$ & $\$ 6485$ & $\$ 6184$ & $-\$ 781$ \\
\multirow{2}{*}{ Melbourne } & N1 & $-\$ 1524$ & $\$ 3864$ & $\$ 13$ & $-\$ 1267$ \\
& N2 & $-\$ 2005$ & $-\$ 2442$ & $-\$ 892$ & $-\$ 2404$ \\
(b) Discount rate of 7\% & $-\$ 1969$ & $-\$ 1328$ & $\$ 1352$ & $-\$ 2131$ \\
Brisbane & N2 & $-\$ 1782$ & $-\$ 301$ & $\$ 2171$ & $-\$ 1987$ \\
& N3 & $-\$ 1837$ & $-\$ 1497$ & $-\$ 692$ & $-\$ 2209$ \\
Melbourne & N1 & $-\$ 2056$ & $-\$ 4376$ & $-\$ 1105$ & $-\$ 2728$ \\
& N2 & $-\$ 2042$ & $-\$ 3868$ & $-\$ 35$ & $-\$ 2603$ \\
\hline
\end{tabular}


Table 11 Mean NPV when mislabeled windows are installed

\begin{tabular}{lllll}
\hline \multirow{5}{*}{$\begin{array}{lllll}\text { Design } \\
\text { wind } \\
\text { classification }\end{array}$} & RF & WS & IW \\
\cline { 3 - 5 } Brisbane & N2 & $-\$ 1439$ & $\$ 5531$ & $-\$ 1016$ \\
& N3 & $-\$ 1365$ & $\$ 8063$ & $-\$ 1073$ \\
Melbourne & N2 & $-\$ 1994$ & $-\$ 2062$ & $-\$ 2357$ \\
\hline
\end{tabular}

This increases the cumulative expected losses to 2070 by $32 \%, 4 \%$ and $96 \%$ for the Brisbane house (N2), Melbourne house (N2) and Brisbane house (N3), respectively. Table 11 shows the mean NPVs for adaptation measures RF, WS and IW if the mislabelled windows are installed. It is suggested that RF and IW is still not costeffective, and WS is cost-effective for Brisbane houses. When mislabelled windows are installed, there is an approximately twofold and tenfold increase of the mean NPV yielded by WS for Brisbane houses with a design wind classification of N2 and N3, respectively, compared to that without such construction error. This implies that the adverse effects of construction error of using mislabelled windows can be largely counter-balanced by installing window shutters.

\section{Conclusions}

In this study, several climate adaptation measures are adopted for Australian contemporary houses subjected to non-cyclonic windstorms to either reinforce the building envelope or increase water resistance of the building interior. A probabilistic risk assessment was conducted considering the effect of construction defects, and a risk-based cost-benefit analysis was then used to evaluate the costeffectiveness of these adaptation measures. The risk analysis results suggest that the annual expected losses for houses in Brisbane with construction defects are considerably higher than those without considering construction defects, whereas the influence of construction defects is slight for the Melbourne houses. The cost-benefit analysis reveals that strengthening windows by increasing window ratings (e.g. N1 to N2, N2 to N3) is cost-effective for Brisbane houses and Melbourne houses. Installing window shutters significantly reduces economic risks incurred by wind and rainfall damage and is cost-effective for houses in Brisbane. The adverse effects of construction error of using mislablled windows can be largely counter-balanced by installing window shutters. Installation of window shutters as a retrofit also provides many co-benefits and has the potential to attract incentives in annual insurance premium, which makes it a strong candidate for climate adaptation.

\section{Abbreviations}

BTR: Batten-to-rafter/truss; COV: Coefficient of variation; CTB: Cladding-tobatten; FE: Finite element; IW: Increase water-resistance of building interior; MCS: Monte Carlo simulation; NPV : Net present value; PRA: Probabilistic risk assessment; RCP: Representative concentration pathway; RF: Strengthen roof; RTW: Rafter/truss-to-wall; WR: Increase window resistance; WS: Install window shutters

\section{Acknowledgements}

The first author acknowledges the support from Australian government research training program scholarship.

\section{Authors' contributions}

$\mathrm{HQ}$ conceived the specific methods, conducted the analysis, interpreted the results and drafted the manuscript. MS conceived the framework, provided insights and discussions on the methods, and substantially revised the manuscript. The author(s) read and approved the final manuscript.

\section{Funding}

Not applicable.

\section{Availability of data and materials}

The datasets used and/or analyzed during the current study are available from the corresponding author on reasonable request.

Ethics approval and consent to participate

Not applicable.

\section{Consent for publication}

Not applicable.

\section{Competing interests}

The authors declare that they have no competing interests.

Received: 7 October 2019 Accepted: 8 January 2020

Published online: 23 March 2020

\section{References}

1. ABS (2011) Australian social trends December 2011: components of household wealth. Australian Bureau of Statistics, Canberra

2. AS 2047 (2014) Windows and external glazed doors in buildings. Standards Australia, Sydney

3. AS 4055 (2012) Wind loads for housing. Standards Australia, Sydney

4. AS/NZS 1170.2 (2011) Structural design actions, part 2: wind actions. Standards Australia, Sydney

5. AS/NZS 2588 (2018) Gypsum plasterboard. Standards Australia, Sydney

6. Bastidas-Arteaga E, Stewart MG (2019) Climate adaptation engineering: risks and economics for infrastructure decision-making, 1st edn. ButterworthHeinemann, Elsevier, Oxford

7. BITRE (2008) About Australia's regions. Bureau of Infrastructure, Transport and Regional Economics, Canberra

8. Dowdy A et al (2015) In: Ekström M et al (eds) East Coast cluster report, climate change in Australia projections for Australia's natural resource management regions: cluster reports. CSIRO and Bureau of Meteorology, Australia

9. Eagleson PS (1972) Dynamics of flood frequency. Water Resour Res 8(4): 878-898

10. Grose M et al (2015) In: Ekström M et al (eds) Southern slopes cluster report, climate change in Australia projections for Australia's natural resource management regions: cluster reports. CSIRO and Bureau of Meteorology, Australia

11. Hamid S, Kibria BG, Gulati S, Powell M, Annane B, Cocke S et al (2010) Predicting losses of residential structures in the state of Florida by the public hurricane loss evaluation model. Statist Methodol 7(5):552-573

12. HAZUS (2014) Multi-hazard Loss estimation methodology - hurricane model. Hazus-MH 2.1 Technical Manual, Federal Emergency Management Agency, Mitigation Division, Washington, DC

13. Henderson DJ, Ginger JD (2007) Vulnerability model of an Australian highset house subjected to cyclonic wind loading. Wind Struct 10(3):269-285

14. HIA (2018) Window into housing 2018. The Housing Industry Association, Canberra

15. Holmes JD (2015) Wind loading of structures, 3rd edn. CRC Press Boca Raton, Florida

16. Koutsoyiannis D, Onof C, Wheater HS (2003) Multivariate rainfall disaggregation at a fine timescale. Water Resour Res 39(7):1173 
17. Lambert M, Kuczera G (1998) Seasonal generalized exponential probability models with application to interstorm and storm durations. Water Resour Res 34(1):143-148

18. Leitch C, Ginger J, Harper B, Kim P, Jayasinghe N, Somerville L (2009) Investigation of performance of housing in Brisbane following storms on 16 and 19 November 2008, Technical Report No. 55. Cyclone Testing Station, James Cook University

19. Li Y, Ellingwood BR (2009) Risk-based decision-making for multi-hazard mitigation for wood-frame residential construction. Aust J Struct Eng 9(1):17-26

20. Li Y, Stewart MG (2011) Cyclone damage risks caused by enhanced greenhouse conditions and economic viability of strengthened residential construction. Nat Hazards Rev 12(1):9-18

21. Orooji F, Friedland CJ (2017) Cost-benefit framework to generate wind hazard mitigation recommendations for homeowners. J Archit Eng 23(4): 04017019

22. Parackal Kl, Humphreys MT, Ginger JD, Henderson DJ (2016) Wind loads on contemporary Australian housing. Aust J Struct Eng 17(2):136-150

23. Parackal Kl, Mason M, Henderson D, Stark G, Ginger J, Somerville L, Harper B, Smith D, Humphreys M (2015) Investigation of Damage: Brisbane, 27 November 2014 Severe Storm Event, Technical Report No. 60. Cyclone Testing Station, James Cook University

24. Pita G, Pinelli JP, Cocke S, Gurley K, Mitrani-Reiser J, Weekes J, Hamid S (2012) Assessment of hurricane-induced internal damage to low-rise buildings in the Florida public hurricane loss model. J Wind Eng Ind Aerodyn 104:76-87

25. Porter KA, Kiremidjian AS, LeGrue JS (2001) Assembly-based vulnerability of buildings and its use in performance evaluation. Earthquake Spectra 17(2):291-312

26. Qin H, Stewart MG (2019a) Wind and Rain Losses for Metal-clad Contemporary Houses Subjected to Non-cyclonic Windstorms. Preprint from engrxiv.org/8ws6t

27. Qin H, Stewart MG (2019b) Construction defects and wind fragility assessment for metal roof failure: a Bayesian approach. Reliability Eng System Saf, in press. https://doi.org/10.1016/j.ress.2019.106777

28. Qin H, Stewart MG (2019c) System fragility analysis of roof cladding and trusses for Australian contemporary housing subjected to wind uplift. Struct Saf 79:80-93

29. Rawlinsons (2015) Rawlinsons Construction Cost Guide 2015. Rawlinsons Publishing, Perth

30. RLB (2019) Riders Digest, 47th edn. Rider Levett Bucknall, Australia

31. Satheeskumar N, Henderson DJ, Ginger JD, Wang CH (2016) Wind uplift strength capacity variation in roof-to-wall connections of timber-framed houses. J Archit Eng 22(2):04016003

32. Sivapalan M, Blöschl G (1998) Transformation of point rainfall to areal rainfall: intensity-duration-frequency curves. J Hydrol 204(1-4):150-167

33. Smith D, Henderson D (2015) Suncorp group limited: cyclone resilience research - phase II. Report TS1018, Cyclone Testing Station, James Cook University, Australia

34. Smith D, Henderson D, Ginger J, Wehner M, Ryu H, Edwards M (2016) Improving the resilience of existing housing to severe wind events: annual project report 2015-2016. Bushfire and Natural Hazards CRC

35. Stewart MG (2003) Cyclone damage and temporal changes to building vulnerability and economic risks for residential construction. J Wind Eng Ind Aerodyn 91(5):671-691

36. Stewart MG (2015) Risk and economic viability of housing climate adaptation strategies for wind hazards in Southeast Australia. Mitig Adapt Strateg Glob Chang 20(4):601-622

37. Stewart MG, Bastidas-Arteaga E (2019) Introduction to climate adaptation engineering. In: Bastidas-Arteaga E, Stewart MG (eds) Climate Adaptation Engineering: Risks and Economics for Infrastructure Decision-Making

38. Stewart MG, Ginger JD, Henderson DJ, Ryan PC (2018) Fragility and climate impact assessment of contemporary housing roof sheeting failure due to extreme wind. Eng Struct 171:464-475

39. Stewart MG, Wang X, Willgoose GR (2014) Direct and indirect cost-andbenefit assessment of climate adaptation strategies for housing for extreme wind events in Queensland. Nat Hazards Rev 15(4):04014008

40. Straube JF, Burnett EFP (2000) Simplified prediction of driving rain on buildings. In: Proceedings of the international building physics conference. Eindhoven University of Technology, Eindhoven

41. Torkian BB, Pinelli JP, Gurley K, Hamid S (2013) Cost-and-benefit evaluation of windstorm damage mitigation techniques in Florida. Nat Hazards Rev 15(2):150-157
42. Unnikrishnan VU, Barbato M (2016) Performance-based comparison of different storm mitigation techniques for residential buildings. J Struct Eng 142(6):04016011

43. Walker GR (2011) Modelling the vulnerability of buildings to wind - a review. Can J Civ Eng 38(9):1031-1039

44. Wang CH, Wang $X$, Khoo YB (2013) Extreme wind gust hazard in Australia and its sensitivity to climate change. Nat Hazards 67(2):549-567

45. Yazdani N, Dowgul RW, Manzur T (2010) Deficiency analysis of coastal buildings toward storm damage reduction. J Perform Constr Facil 24(2):128137

46. Zscheischler J, Westra S, Hurk BJ, Seneviratne SI, Ward PJ, Pitman A et al (2018) Future climate risk from compound events. Nat Clim Chang 8:469477

\section{Publisher's Note}

Springer Nature remains neutral with regard to jurisdictional claims in published maps and institutional affiliations.

\section{Submit your manuscript to a SpringerOpen ${ }^{\circ}$ journal and benefit from:}

- Convenient online submission

- Rigorous peer review

- Open access: articles freely available online

- High visibility within the field

- Retaining the copyright to your article

Submit your next manuscript at $\boldsymbol{\nabla}$ springeropen.com 